\title{
Synthesis, Characterization and Applications of $\mathrm{Zno} / \mathrm{TiO}_{2} / \mathrm{Sio}_{2}$ Nanocomposite
}

\section{CHITRA MANOHARAN ${ }^{1,2}$, VENCKATESH RAJENDRAN ${ }^{\star 2}$ and RAJESHWARI SIVARAJ ${ }^{2}$}

\author{
${ }^{1}$ Research Scholar, R\&D Centre, Bharathiar University, Coimbatore - 641046 , India. \\ ${ }^{2}$ Department of Chemistry, Government Arts College, Udumalpet - 642 126, India. \\ *Corresponding author E-mail: rvenckat@gmail.com
}

http://dx.doi.org/10.13005/ojc/340319

(Received: November 16, 2017; Accepted: February 17, 2018)

\begin{abstract}
$\mathrm{ZnO} / \mathrm{TiO}_{2} / \mathrm{SiO}_{2}$ nanocomposite was synthesized using microwave assisted sol-gel method and characterized using UV-Visible spectroscopy, XRD, SEM, EDX, FT-IR and TEM analysis. XRD results showed the crystallite in anatase phase. FT-IR reports bands that appeared at 1108 and 862 $\mathrm{cm}$ - 1 which shows the formation of $\mathrm{Si}-\mathrm{O}-\mathrm{Si}$ and $\mathrm{Zn}-\mathrm{O}-\mathrm{Ti}$ bonds. SEM and EDX analysis showed the incorporation of $\mathrm{ZnO}$ nanoparticle with the $\mathrm{TiO}_{2} / \mathrm{SiO}_{2}$ nanocomposite which increase the separation of electron-hole pairs and can enhance in photocatalytic activity on methylene blue dye under sunlight irradiation. Ultrasound irradiation was applied for the impregnation of ZTS nanocomposite with homogeneous distribution on cotton fabrics. The antibacterial activities of the ZTS impregnated cotton fabrics observed against Escherichia coli (Gram negative) and Staphylococcus aureus (Gram positive) cultures was significant. The effectiveness of fabric treatment is assessed by excellent Ultraviolet protection factor (UPF).
\end{abstract}

Keywords: Nanocomposite, Microwave irradiation, X-ray diffraction, SEM, TEM, Antibacterial activity.

\section{INTRODUCTION}

Metal oxide nanoparticles have attracted great attention in recent years on account of their special electronic and chemical properties ${ }^{1}$. Titanium dioxide $\left(\mathrm{TiO}_{2}\right)$ is mostly used due to its high physical and chemical stability, low cost and toxicity ${ }^{2,3}$. Due to the large band gap of silicon dioxide $\left(\mathrm{SiO}_{2}\right)$, enhances the photocatalytic activity of other oxide materials with the addition of $i^{4}, 5$. Kim et al., ${ }^{6}$ also proposed that, the introduction of silicondioxide to other metaloxides increases the band gap energy. $\mathrm{TiO}_{2} / \mathrm{SiO}_{2}$ composite has increased potential application in the field of varied photocatalysis, as they show improved photocatalytic and thermal properties simultaneously when compared to pure $\mathrm{TiO}_{2}{ }^{7}$. Coupled semiconductor photocatalyst of $\mathrm{TiO}_{2} / \mathrm{ZnO}$ has been reported to enhance the photo

This is an Open Access article licensed under a Creative Commons Attribution-Non Commercial-Share Alike 4.0 International License (https://creativecommons.org/licenses/by-nc-sa/4.0/), which permits unrestricted Non Commercial use, distribution and reproduction in any medium, provided the original work is properly cited. 
degradation efficiency of $\mathrm{TiO}_{2}$ catalyst and studies on improving the photocatalytic efficiency have been reported $^{8-11}$. Zinc oxide has achieved applications in various areas such as optical, magnetic and gas sensing and apart from these, zinc compounds have been generally regarded as safe ${ }^{12}$. In recent years, $\mathrm{ZnO}$ and $\mathrm{TiO}_{2}$ nanostructures have attracted great attention in both fundamental studies and applications ${ }^{13}$.

The rapid heat transfer of microwave irradiation allows the chemical reactions much faster as compared to usual heating methods, ensuing increased product yield. ${ }^{14}$ The kinetic or thermodynamic pathways of the temperature sensitive reactions can be selectively tuned by microwave irradiation ${ }^{14}$. Microwave synthesis is the convenient method for the synthesis of metal oxide semiconductor nanoparticle ${ }^{15}$. Nano coating on the surface of textiles and clothing enhance the material for UV blocking; antimicrobial and self-cleaning properties have also been reported ${ }^{16}$.

Sonochemical irradiation has been proven as an effective technique for the synthesis ${ }^{17}$, as well as for the deposition and insertion of nanoparticle on/into fabrics ${ }^{18-20}$. The deposition of nanoparticles on fabrics involves the formation of microjets from auditory bubble, which push the nanoparticle onto the surface of the fabric at a high speed causes ${ }^{21}$.

The aim of this work is to synthesize and characterize the ZTS nanocomposite using microwave assisted sol-gel method. The photocatalytic studies were performed for methylene blue dye and antibacterial activity of the sonochemically coated cotton fabrics has also been investigated.

\section{MATERIALS AND METHODS}

\section{Materials}

The chemicals such as titanium tetraisopropoxide (TTP) ( $\mathrm{Ti}\left\{\mathrm{OCH}\left(\mathrm{CH}_{3}\right) 2\right\} 4$,99.9\%, Merck \& Co.), as a titanium precursor, Silicic acid $\left(\mathrm{H}_{2} \mathrm{SiO}_{3}, 99.9 \%\right.$, Merck) as silica source, zinc acetate dihydrate $\left(\mathrm{Zn}\left(\mathrm{CH}_{3} \mathrm{COO}\right)_{2} \cdot 2 \mathrm{H}_{2} \mathrm{O}, 98.0 \%\right.$, Merck \& Co. $)$ as zinc oxide source, Congo red (Merck \& Co.), ethanol $\left(\mathrm{C}_{2} \mathrm{H}_{5} \mathrm{OH}, 99.9 \%\right.$, Merck \& Co. $)$, hydrochloric acid $(\mathrm{HCl})(99.9 \%$, Merck \& Co.), isopropanol $\left(\left(\mathrm{CH}_{3}\right)_{2} \mathrm{CHOH}, 99.0 \%\right.$, Merck \& Co.), tetrahydrofuran
(THF) $\left(\left(\mathrm{CH}_{2}\right)_{4} \mathrm{O}, 99.5 \%\right.$, Merck \& Co. $)$ and potassium hydroxide $(\mathrm{KOH})(85.0 \%$, Merck \& Co.) were used in this study.

\section{Synthesis of $\mathrm{ZnO} / \mathrm{TiO}_{2} / \mathrm{SiO}_{2}$ nanocomposite}

Firstly, ZnO nanoparticle were synthesized by alkali precipitation method from the aqueous solution of $\mathrm{Zn}\left(\mathrm{CH}_{3} \mathrm{COO}\right)_{2} \cdot 2 \mathrm{H}_{2} \mathrm{O}$ and $\mathrm{KOH}^{22}$.

$\mathrm{TiO}_{2} / \mathrm{SiO}_{2}$ sol was prepared by mixing the sols of $\mathrm{TiO}_{2}$ and $\mathrm{SiO}_{2}$, which were prepared by stirring $\mathrm{HCl}$, ethanol and TTIP (Titanium tetraisopropoxide) (1:4:2 ratio) and silicic acid with THF (Tetrahydrofuran) $(1: 2 \text { ratio })^{23}$.

The $\mathrm{ZnO}$ suspension was prepared by dispersing the calculated amount of $\mathrm{ZnO}$ in $100 \mathrm{ml}$ deionised water, and isopropanol was added to the mixture in order to immerse $\mathrm{ZnO}$ thoroughly. Then the suspension was added to the $\mathrm{TiO}_{2} / \mathrm{SiO}_{2}$ sol, stirred magnetically for 30 minutes. The resulting aqueous solution was introduced in microwave irradiation for 15 minutes. The reaction products were filtered and washed with deionised water followed by ethanol to remove the ions probably left over in the final product and dried in hot air oven at $80{ }^{\circ} \mathrm{C}$ to obtain the ZTS nanocomposite.

\section{Characterization of synthesized nanocomposite}

The optical properties of the synthesized $\mathrm{ZnO} / \mathrm{TiO}_{2} / \mathrm{SiO}_{2}$ nanocomposite were analysed using UV-Visible spectrophotometer (UV-1700 Series, Shimadzu), the crystalline structure analysed by D8 Advance X-ray diffraction (Shimadzu lab X-6000). Surface morphology was determined by scanning electron microscopy (SEM) (Model JSM 6390LV, JOEL, USA), the elemental analysis by EDX and the functional groups by Fourier transform infrared spectroscopy (FTIR) (Bruker, Germany). The morphology and size were determined by transmission electron microscopy (TEM) (JEOL JEM-3100F).

The photocatalytic activity of the synthesized ZTS nanocomposite was studied by the decolourization of the aqueous solution of methylene blue under sunlight. All the experiments were carried out in an open $100 \mathrm{ml}$ Pyrex vessel under identical conditions ${ }^{24}$. The experiments were conducted at different concentrations $(20,40,60,80,100 \mathrm{mg} / \mathrm{l})$ 
of dye solutions at a photocatalyst load from 0.1 to $0.5 \mathrm{~g}$. The efficiency of the catalyst was calculated using the following equation

$$
R(\%)=(A 0-(A / A 0)) \times 100
$$

Where $A O$ and $A$ are the absorbance of dye solution before and after decolourization respectively ${ }^{25}$.

The coating process was carried out by using ultrasonicator. 1 piece of $10 \times 10 \mathrm{~cm}$ fabric (100\% cotton) and ZTS nanocomposite was added to the solution of $4: 1$ ethanol/ ethylene glycol in a $100 \mathrm{ml}$ sonication flask. The sonication was conducted by $70 \%$ amplitude of $750 \mathrm{~W}$ booster sonicator (Ti-horn, $20 \mathrm{kHz}$ ). The reaction mixture was irradiated for $2 \mathrm{~h}$ with high intensity ultrasonic horn and the fabric was washed with ethanol and dried out under vacuum ${ }^{21}$.

The morphology of the cotton fabric alone and the nanocomposite coated cotton fabrics were studied by SEM analysis. The UPF (Ultraviolet protecting Factor) of ZTS nanocomposite coated cotton fabric was assessed by using the most accepted standard AATCC test method 183.

The antibacterial activity of the cotton fabrics against Staphylococcus aureus (Gram positive) and Escherichia coli (Gram negative) bacteria strains were tested using well diffusion method ${ }^{26,27}$.

\section{RESULTS AND DISCUSSION}

Characterization of synthesized ZTS nanocomposite

UV-Vis absorption spectra of ZTS nanocomposite is shown in Fig. 1. The peak observed at about $222 \mathrm{~nm}$ can be attributed to the transfer of an electron from $\mathrm{O}^{2-}$ to $\mathrm{Ti}^{4+}$ ions of the highly dispersed tetrahedral coordinated $\mathrm{TiO}_{4}$ unit. Anbo et al., have reported that the tetrahedral coordination of titanium oxides can be chemically supported onto silica matrix ${ }^{28}$. An excitonic absorption peak is found at about $248 \mathrm{~nm}$ due to the $\mathrm{ZnO}$ nanoparticle which lie much higher than the band gap wavelength of $358 \mathrm{~nm}(\mathrm{Eg}=3.46 \mathrm{eV})$ due to the inverse relationship of the energy of a photon $(E)$ and the wavelength of the light $(\lambda)^{29}$

FT-IR spectrum of the ZTS nanocomposite (Fig. 2) has two distinctive bands that appeared at around $862 \mathrm{~cm}^{-1}$ and $1108 \mathrm{~cm}^{-1}$ which are responsible for $\mathrm{TiO}_{2}, \mathrm{ZnO}$ and $\mathrm{SiO}_{2}$ matrix in the nanocomposite.

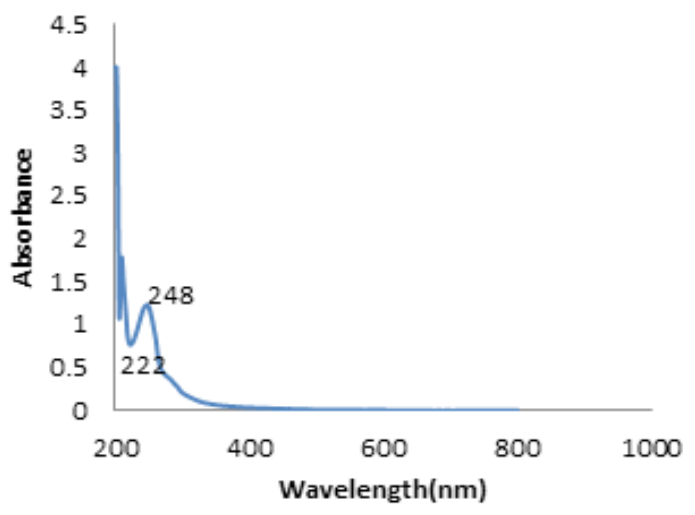

Fig. 1. UV-Visible spectra of ZTS nanocomposite

The peak at $1108 \mathrm{~cm}^{-1}$ show Si-O-Si bending vibrations ${ }^{23}$ and the peak around at $862 \mathrm{~cm}^{-1}$ can be devoted to symmetric stretching vibration mode of $\mathrm{Zn}-\mathrm{O}-\mathrm{Ti}$ groups ${ }^{25,30,31}$. Stretching vibrations of $\mathrm{Zn}-\mathrm{O}-\mathrm{Si}$ was found to be absent as no band appeared at $950 \mathrm{~cm}^{-1}$ 32. The peaks observed at $1621 \mathrm{~cm}^{-1}$ and at above $3000 \mathrm{~cm}^{-1}$ indicates the bending and stretching vibrations of $-\mathrm{OH}$ groups ${ }^{23}$.

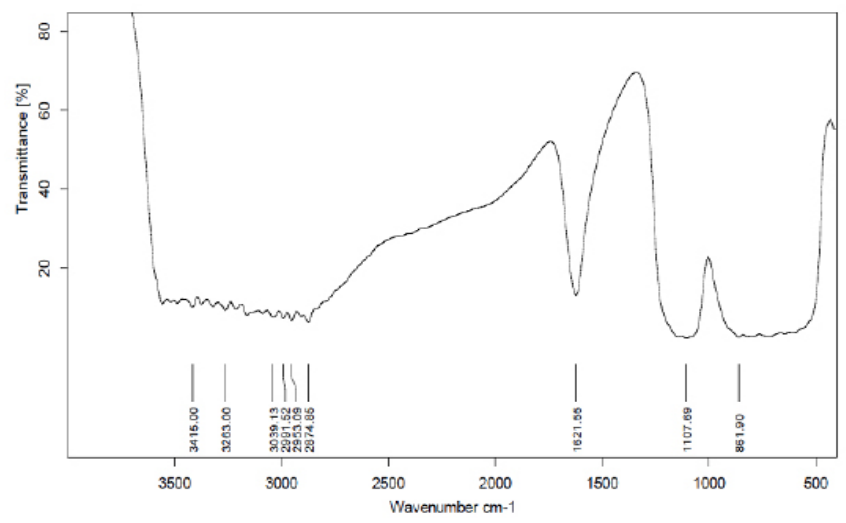

Fig. 2. FT-IR Spectra of ZTS nanocomposite 
Figure 3 shows the XRD pattern of ZTS nanocomposite which confirms the phase formation and crystalline nature of the samples. The size of the nanoparticle (D) has been calculated by the most intense XRD line using Scherer's formula.

$D=k \lambda / \beta \operatorname{Cos} \theta$

Where $\lambda$ is the wavelength of $X$-ray, $\beta$ is the full width half maxima, $\theta$ is Bragg's angle, $k$ is the shape factor which has the value 0.9 . The most intense peak (20) at 25.30 assigned for anatase $\mathrm{TiO}_{2}$ (d101) was observed in the ZTS nanocomposite ${ }^{23}$. The broad peaks observed ( $2 \theta)$ at about 20.6, 22.20 indicates that the overlapping of 100 plane (quartz) and the amorphous state of $\mathrm{SiO}_{2}$ respectively ${ }^{33}, 34$. The diffraction peaks observed $(2 \theta)$ at $37,47.90$ are indexed as 101 and 102 planes of $\mathrm{ZnO}$ hexagonal wurzite phase and $54.4,630$ for $\mathrm{ZnTiO}_{3}^{1,24,35}$. The crystallite size of ZTS nanocomposite, calculated from the most intense peak was about $46 \mathrm{~nm}$.

Figure 4 shows the SEM image of ZTS nanocomposite in which $\mathrm{TiO}_{2}$ nanoparticle are deposited on the surface of the $\mathrm{SiO}_{2}$ spheres and there were no isolated $\mathrm{TiO}_{2}$ particles formed separately ${ }^{36}$. $\mathrm{ZnO}$ nanoparticle was coordinate with the surface of the $\mathrm{TiO}_{2} / \mathrm{SiO}_{2}$ nanocomposite as view as white patches. The EDAX results showed the atomic ratio of $\mathrm{Zn} / \mathrm{Ti} / \mathrm{Si}$ as $52.54 / 19.66 / 8.05$. The results show $\mathrm{ZnO}$ to be incorporated into $\mathrm{TiO}_{2} / \mathrm{SiO}_{2}$ to form ZTS nanocomposite (Figure 5).

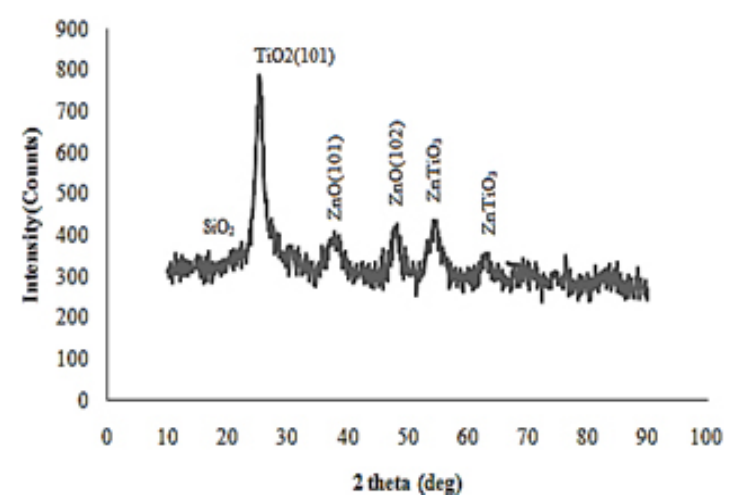

Fig. 3. XRD Analysis of ZTS nanocomposite

Figure 6 clearly refers the morphology of the composites to be spherical shape and some of the composites as agglomerates with the mean crystallite size of $46-50 \mathrm{~nm}$ which is approximately in conformity with XRD.

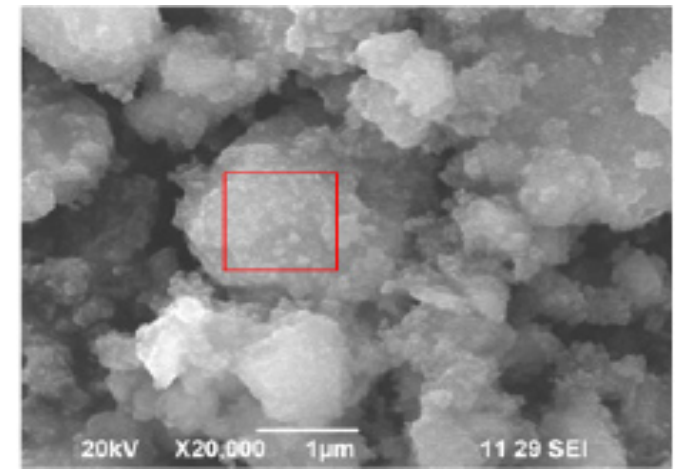

Fig. 4. SEM Analysis of ZTS nanocomposite

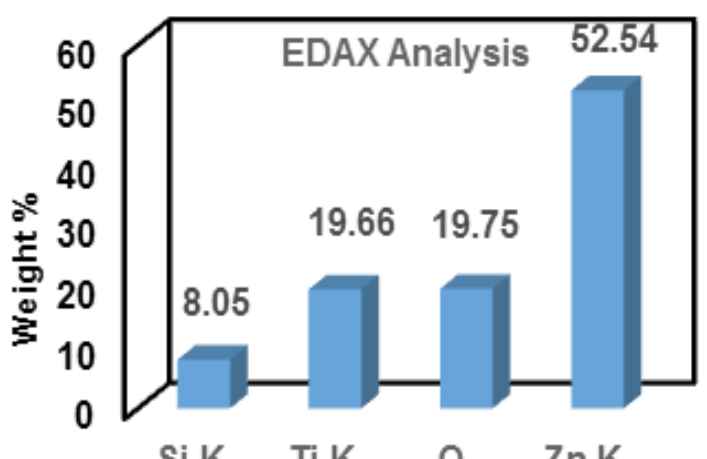

$\begin{array}{llll}\text { Si K Ti K } & 0 & \text { Zn K }\end{array}$

Fig. 5. EDAX of ZTS nanocomposite

\section{Photocatalytic activity}

The photocatalytic activity of ZTS nanocomposite was measured by photo decomposition of methylene blue by using sunlight as the light source by taking into consideration of various parameters such as contact time, catalyst dosage and $\mathrm{pH}$.

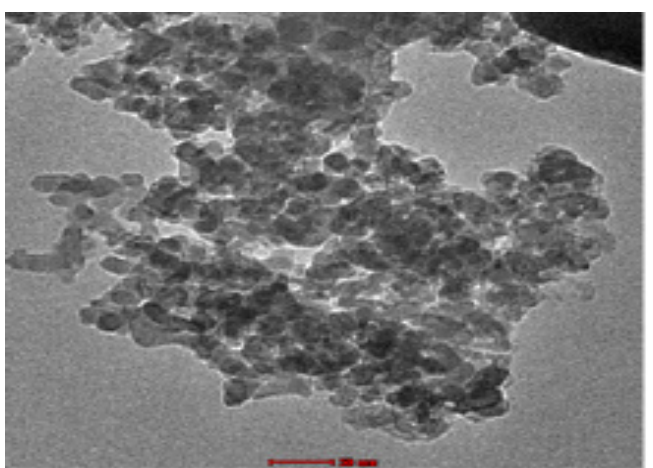

Fig. 6. TEM analysis of ZTS nanocomposite

Effect of contact time and initial concentration of the dye

The removal of methylene blue was evaluated for various concentrations of dye ranging 
from 20 to 100 ppm (as per industry usage) at different time periods were shown in Fig. 7(a). It depicts that an increase in dye removal with increase in time and reached the optimal at $180 \mathrm{~min}$. As the dye concentration was increased from 20 to $100 \mathrm{ppm}$, the removal of dye decrease from $100 \%$ to $90 \%$ at equilibrium. It is clear that the removal of dye depends on the time and initial concentration of the dye.

\section{Effect of Catalyst Loading}

The dosage of the nanocomposite decides the capacity of the photocatalyst for the concentration of the dye solution. The results are shown in Fig. 7(b) which shows that the percentage removal of the dye increased rapidly with increase in catalyst dose $(0.1$ to $0.5 \mathrm{~g} / \mathrm{l})$ and after optimum dose, the removal percentage remained constant. The availability of the active sites on the photocatalyst surface, increasing the number of $\mathrm{OH}$ radicals with the increase in dosage, resulting the decolourisation of dye solution ${ }^{37}$.

\section{Effect of pH}

The $\mathrm{pH}$ of the reaction has a significant effect on the surface properties of the catalyst, which include the surface charge of the particles. The effect of $\mathrm{pH}$ on the photocatalytic degradation of methylene blue showed higher the $\mathrm{pH}$, higher is the decomposition of the dye, Fig. 7(c). at $\mathrm{pH} 2$, the maximum decomposition was $11 \%$ and with increase in the $\mathrm{pH} 12$, the degradation percentage reached $90 \%$, at lesser time than equilibrium which may be due to the surface charges. The electrostatic attraction of the negatively charged sites and the dye cation favoured the decomposition of the dye by the $\mathrm{pH}$ increases ${ }^{38}$.

Figure 8 shows the FT-IR spectrum of ZTS nanocomposite after decomposition of methylene blue dye. The appearance of characteristic bands of ZTS $\left(1100,860 \mathrm{~cm}^{-1}\right)$ and there is no band appeared at around $782 \mathrm{~cm}^{-1}$ which is the characteristic band for C-S functionality ${ }^{39}$, shows that the cleavage of the
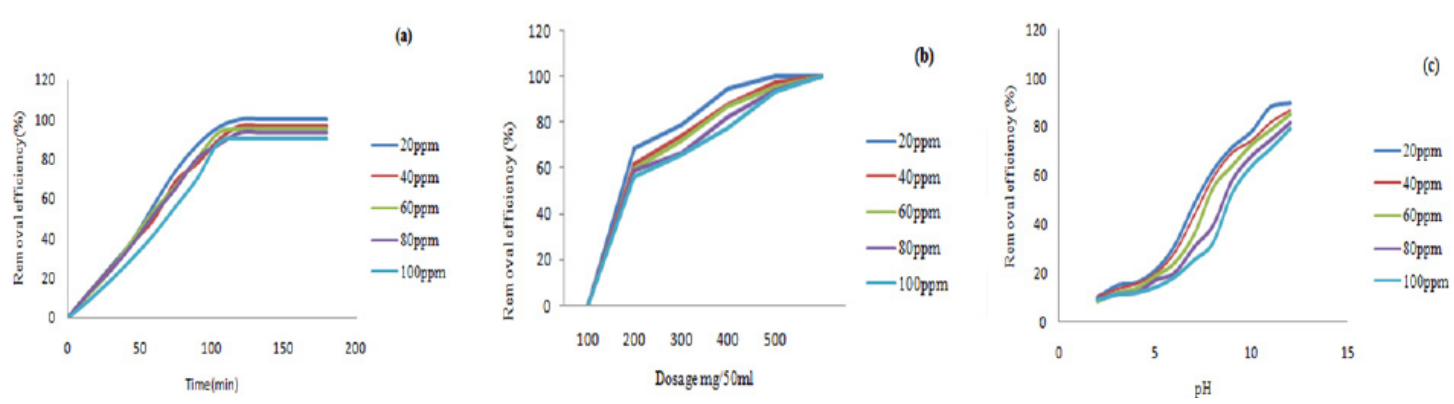

Fig. 7. Effect of (a) contact time on removal of methylene blue (b) Dosage of catalyst on removal methylene blue (c) $\mathrm{pH}$ on removal of methylene blue

$\mathrm{C}-\mathrm{S}+=\mathrm{C}$ functional group in methylene blue, by the $\mathrm{OH} \bullet$ radicals generated by the oxidation of water by holes formed by ZTS.Columbic interaction with the surface of ZTS and the cleavage of the bonds occur. The conversion of $\mathrm{C}-\mathrm{S}+=\mathrm{C}$ to $\mathrm{C}-\mathrm{S}(=\mathrm{O})-\mathrm{C}$ induces the opening of the central aromatic ring through the heteroatoms, $\mathrm{S}$ and $\mathrm{N}^{40}$.

\section{Structure and morphology of the nanocomposite coated fabrics}

Figure $9 \mathrm{a}$ and $9 \mathrm{~b}$ shows the cotton fabrics before and after sonochemical treatment. Fig.10b shows a uniform distribution of the particles along

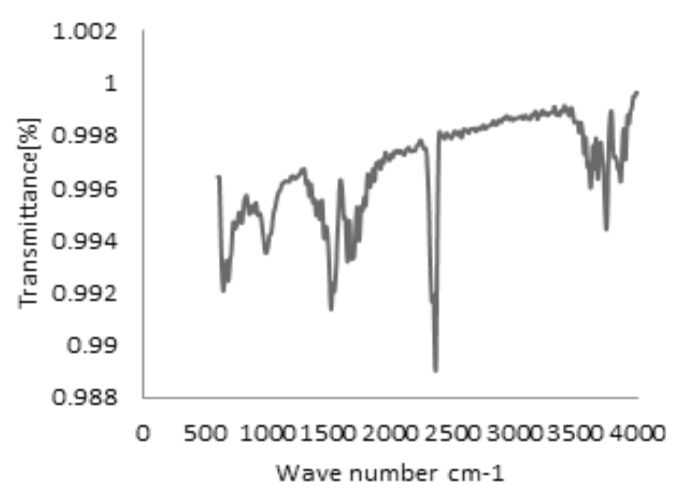

Fig. 8. FT-IR Spectra of ZTS after decomposition of methylene blue 
the fibre which shows that ultrasound irradiation can be used as an effective method for coating textiles.

The UV-protection factor rating of the ZTS coated cotton fabric was in the range of $>50$ and the transmission percentage was less than 2.5 which are related to the standard UV-protection factors rating (Table 1).

The UPF values were obtained against minimum transmission (i.e. Maximum UPF) of UV radiation in the range of $387-388 \mathrm{~nm}$ for five scans, thus conforming the ability of ZTS to work effectively in UV-A range (320-400 nm), recognised as a major cause of pigmentation and premature ageing ${ }^{41}$.
Table1: Standard UPF Values

\begin{tabular}{lcc}
\hline UPF Range & $\begin{array}{c}\text { Protection } \\
\text { Category }\end{array}$ & $\begin{array}{c}\text { UV-R } \\
\text { Transmission (\%) }\end{array}$ \\
\hline $15-24$ & Good & $6.7-4.2$ \\
$25-39$ & Very good & $4.1-2.6$ \\
$40-50,>50$ & Excellent & Less than 2.5 \\
\hline
\end{tabular}

Figure 10 reports the antibacterial activity of the ZTS nanocomposite coated cotton fabrics tested against Staphylococcus aureus and Escherichia coli bacteria strains. Strong bactericidal effect was observed for the nanocomposite coated clothes for both bacteria strains $(19 \mathrm{~mm}$ zone of inhibition observed for Staphylococcus aureus and $18 \mathrm{~mm}$ for Escherichia coli).
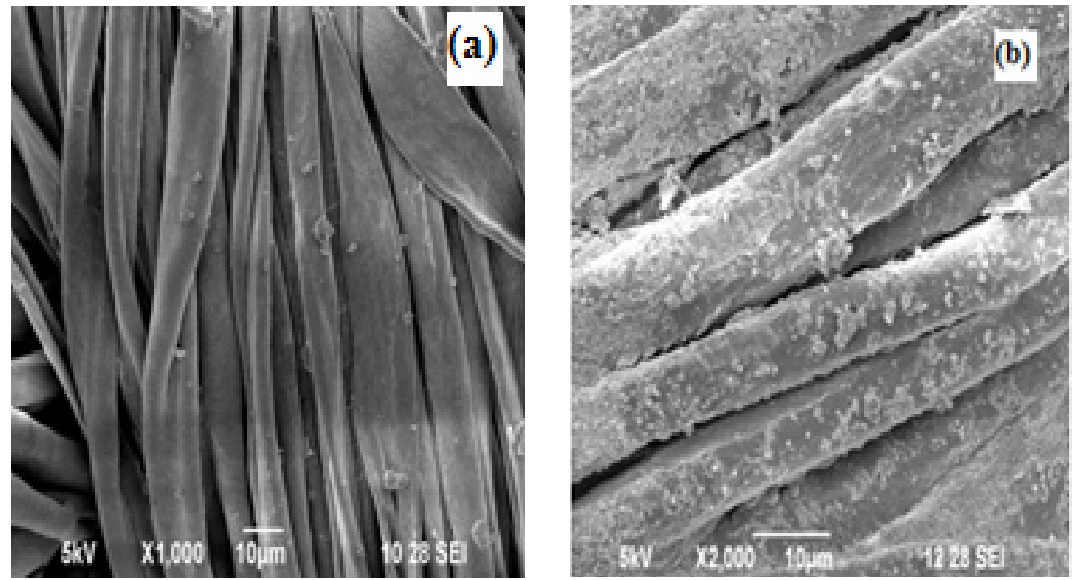

Fig. 9. SEM images of a) uncoated Cotton fabric b) ZTS Coated cotton fabric
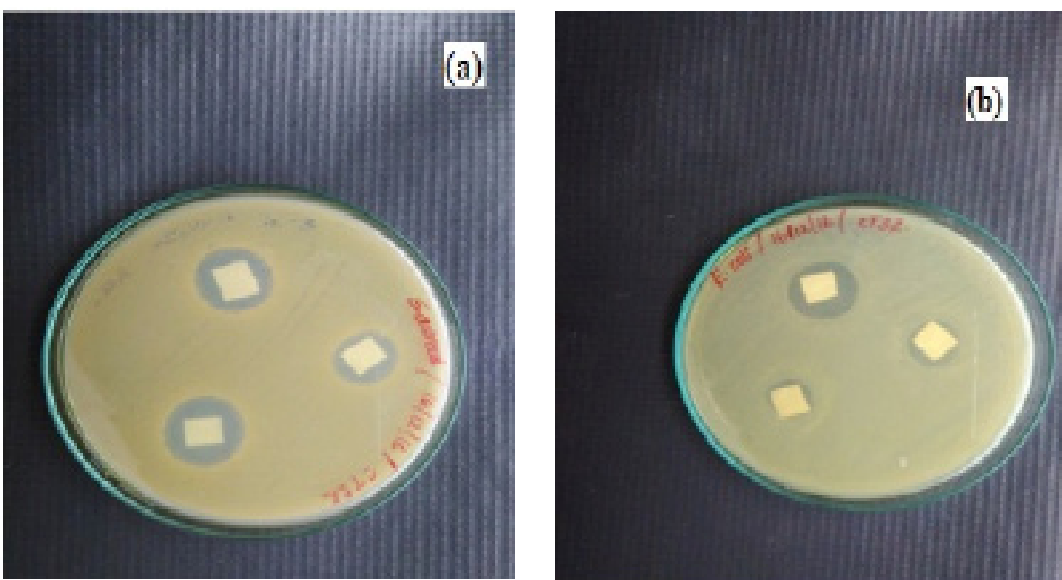

Fig 10. Antibacterial activity of ZTS nano composite coated cotton fabric against a) Staphylococus areas b) E.Coli 


\section{CONCLUSION}

The $\mathrm{ZnO}$ based $\mathrm{TiO}_{2} / \mathrm{SiO}_{2}$ nanocomposite shows efficient photodegradation on methylene blue dye at higher concentration under sunlight. The sonochemical coating method of nanocomposite on fabrics provide a uniform deposition. Strong antibacterial activities and efficient UPF values were observed for the coated cotton fabrics. The nanocomposite coated fabrics can comprise probable applications in wound dressing, as bandages and designing of UV protecting fabrics.

\section{ACKNOWLEDGEMENT}

The authors are grateful to the Bharathiar University, Coimbatore and Karunya University, Coimbatore for instrumentation facility.

\section{REFERENCES}

1. Stoyanova, H.; Hitkova, A.; BachvarovaNedelcleva, R.; Iordanova, N.; Ivanova, M.; Sredkova. Chem. Technol Metallurgy., 2013, 48, 154-161.

2. Diamandeseu, L.F,; Vasiliu, D.; Tarabasanuminaila, M.; Feder, A.M.; Vlaicu, M.; Trodorescu, D.; Macovei, I.; Enculescu, V.; Paravulescu, E.;Vasile. Mater. Chem. Phy., 2008, 112, 146-153.

3. Tong, T.; J. Zhang, B.; Tian, F.; Chen, D.; He. J. Hazard. Mater., 2008, 155, 572-579.

4. Ali, M.; Mohammad Ali, B.; Naser, M. Ind.J. Chem., 2010, 49, 1593-1600.

5. Elias, S.; Panagiotis, L.; Chritophoros, K. J. Phys. Chem. 2001, 105, 3486-3492.

6. Kim, S.W.; Kang, M.; Choung, S.J. J. Ind. Eng., Chem., 2005, 11, 416-424.

7. Nilchi, A.; Janitbar-Darzi, S.; Rasouli-Garmarodi, S. Mater. Sci. Appl., 2011, 2, 476-480.

8. Liao, D.L.; Badour, C.A.; Liao, B.Q. J. Photochem. Photobiol.A:Chem., 2008, 194, 11-19.

9. Wang, J.; Jiang, Z.; Zhang, L.; Kang, P.; Xie, Y.; Lv,Y.; Xu, R.; Zhang, X. Ultrason. Sonochem., 2009, 16, 225-231.

10. Xu, X.; Tian, J.; Wang, X.; Dai, J.; Liu, X. Cer. Intl., 2011, 37, 2201-2206.

11. Janitabar-Darzi, S .; Mahjoub, A.R. J. Alloys Comp., 2009, 486, 805-808.

12. Wahab, A.R.; Mishra, A.; Yun, S.I.; Kim,Y.S. ; Shin, H.S. Appl. Microbiol. Biotechnol., 2010, 87, 1917-1925.

13. Awang, N.J.;Aziz.; Madzlan, M.;Yusoff, A.R.J.Solid St. Sci. and Technol. Letters., 2008, 16, 45-54.

14. Biswa Mohan Sahoo.; Ravikumar, B.V.V.; Panda, I. ; Dinda, S.C. J. Nanoparticles., 2013, 2013, 1-7.

15. Singh, A.K.; Nakate, U.T. J. Nanoparticles.,
2013, 6, 66-70.

16. Hoon Joo Lee. Text Res J., 2005, 75, 551-556

17. Gedanken, A. Ultrason. Sonochem., 2004, 11, 47-55.

18. Kotlyar, A.; Perkas, N.; Amiryan, G.; Meyer, M.; Zimmermann, W.; Gedanken, A. J. Appl. Polym. Sci., 2007, 104, 2868-2876.

19. Pol, V. G.; Srivastava, D. N.; Palchik, O.; Palchik, V.; Slifkin, M. A.; Weiss, A. M.; Gedanken, A. Langmuir., 2002, 18, 3352-3357.

20. Pol, V. G.; Wildermuth, G.; Felsche, J.; Gedanken, A.; Calderon-Moreno, J. J. Nanosci. Nanotechnol., 2005, 5, 975-979.

21. IlanaPerelshtein.; Applerot, G.; Perkas, N.A.; Gedanken, App.Mat.\& Interfaces, 2010, 2, 1999-2004.

22. SiniKuriakose.; Neha Bhardwaj.; Jaspal Singh.; Biswarup Satpati.; Satyabrata Mohapatra.; Beilstein, J. Nanotechnol., 2013, 4, 763-770.

23. Balachandran, K.; Venckatesh, R.; Rajeshwari Sivaraj. Int.J. Eng.Sci. Tech., 2010, 2, 3695-3700.

24. Chandraboss, V.L.; Karthikeyan, B.; Kamalakkannan, J.; Prabha, S.; Senthilvelan, S. Hin. Pub. Cor. J. Nanopar., 2013, 2013,17-24.

25. Tian, J.; Chen, L.; Yin, Y.; Wang, X.; Dai, J.; Zhu, Z.; Liu, X; Wu, P. Surface and Coatings Technology., 2009, 204, 205-214.

26. Kulandhaivel, M.; Palaniswamy, M. International Journal of Pharmaceutical and Biological Archives., 2012, 3, 604-609.

27. Agbabiaka, T.O.; Samuel, T.; Sule ,I. O.; Ethnobotanical Leaflets, 2010, 14, 876-88.

28. Abdolreza Nilchi.; Simin Janitabar-Darzi.; Somayeh Rasouli-Garmarodi. Mate.Sci.Appl., 2011, 2, 476-480. 
29. Zhang, D.H.; Xue, Z.Y.; Wang, Q. P. J. Phys.D., 2002, 35, 2837-2840.

30. Karthik, K.; Pandian, S. K.; Jaya, N.V. Appl. Sur. Sci., 2010, 256, 6829-6833.

31. Wang, J.; Li, J. ;Xie, Y. ; Li, C.; Han, G.; Zhang, L.; Xu, R.; Zhang , X. Journal of Environmental Management., 2010, 91, 677-684.

32. Djouadi, D.; Chelouche, A.; Aksas, A.; Sebais, M. Phy. Procedia., 2009, 2, 701-705.

33. Ruchi Nandanwar.; Purnima Singh.; Fozia Haque, Z. Ame. Che. Sci. Journal, 2015, 5,1-10.

34. Zhong li.; tiejun shi.; liying guo, J. Serb. Chem. Soc., 2010, 75, 385-394.

35. Thambidurai, M.; Jun Young Kim.; Jiyun Song.; Youngjun Ko.; Hyung-jun Song.; Chan-mo Kang.; Muthukumarasamy, N.; Dhayalan Velauthapillai.; Changhee Lee. Elec. Supp.
Mat. (ESI) J. Mat. Chem.C, The Royal Society of Chemistry., 2013, 1, 8161-8166.

36. Mahesh, K.P.O.; Kuo, D.H.; Huang, B.R.; Ujihara, M.; Imae, T. Appl. Catal. A:Gen, 2014, 475, 235-241.

37. Goncalves, M. S. T.; Oliveira-Campos, A. M. F.; Pinto, E. M. M.S.; Plasencia P. M. S. ; Queiroz, M. J. R. P. Chemosphere, 1999, 39, 781-786.

38. Majid Aliabadi.; Toktam Sagharigar. J. Appl. Environ. Biol. Sci., 2011, 1, 620-626.

39. Liang, S.; Guo, X.; Feng, N.; Tian, Q. J. Hazard. Mater., 2010, 174, 756-762.

40 Houas, H.; Lachheb, M.; Ksibi, E.; Elaloui, C.; Guillard, .; Herrmann, J.M. Appl.Catal. B., 2001, 31, 145-157.

41. Chakraborty, J.N.; Vivek Sharma. Preeti Gautam, JTATM., 2014, 9, 1-17. 